\title{
NUEVAS APORTACIONES AL POBLAMIENTO IBÉRICO Y ROMANO DEL NOROESTE MURCIANO: LOS ALTIPLANOS DE ARCHIVEL Y BARRANDA
}

\author{
NEW PERSPECTIVES ON THE IBERIAN AND ROMAN SETTLEMENTS IN NORTHWESTERN MURCIA: \\ THE PLATEAUS OF ARCHIVEL AND BARRANDA
}

\author{
LETICIA LÓPEZ-MONDÉJAR \\ Institute of Archaeology \\ University College London
}

\section{INTRODUCCIÓN: OBJETIVOS Y METODO- LOGÍA}

Los últimos trabajos de campo desarrollados en la comarca Noroeste murciana reflejan la vitalidad de este sector del Sureste durante los periodos ibérico y romano. La importancia de yacimientos como el Cerro de las Fuentes o la recientemente excavada necrópolis del Villar de Archivel, muestran la importante ocupación de esta área durante el periodo ibérico, ofreciendo además interesantes datos para el análisis de su integración en la órbita romana. El objetivo del presente trabajo es analizar los yacimientos localizados en este sector murciano correspondiente al entorno de las poblaciones murcianas de Archivel y Barranda (Figs. 1, 2 y 3 ), y cuya cronología se extiende entre los siglos IV a.C.-II d.C. Se presentan así todos los yacimientos documentados en esta zona a fin de establecer un primer catálogo general de los mismos en el que vean la luz aquellos aun inéditos. Partiendo de dichos datos, y a modo de síntesis general, se plantearán algunos de los rasgos que definen el poblamiento ibérico y romano en

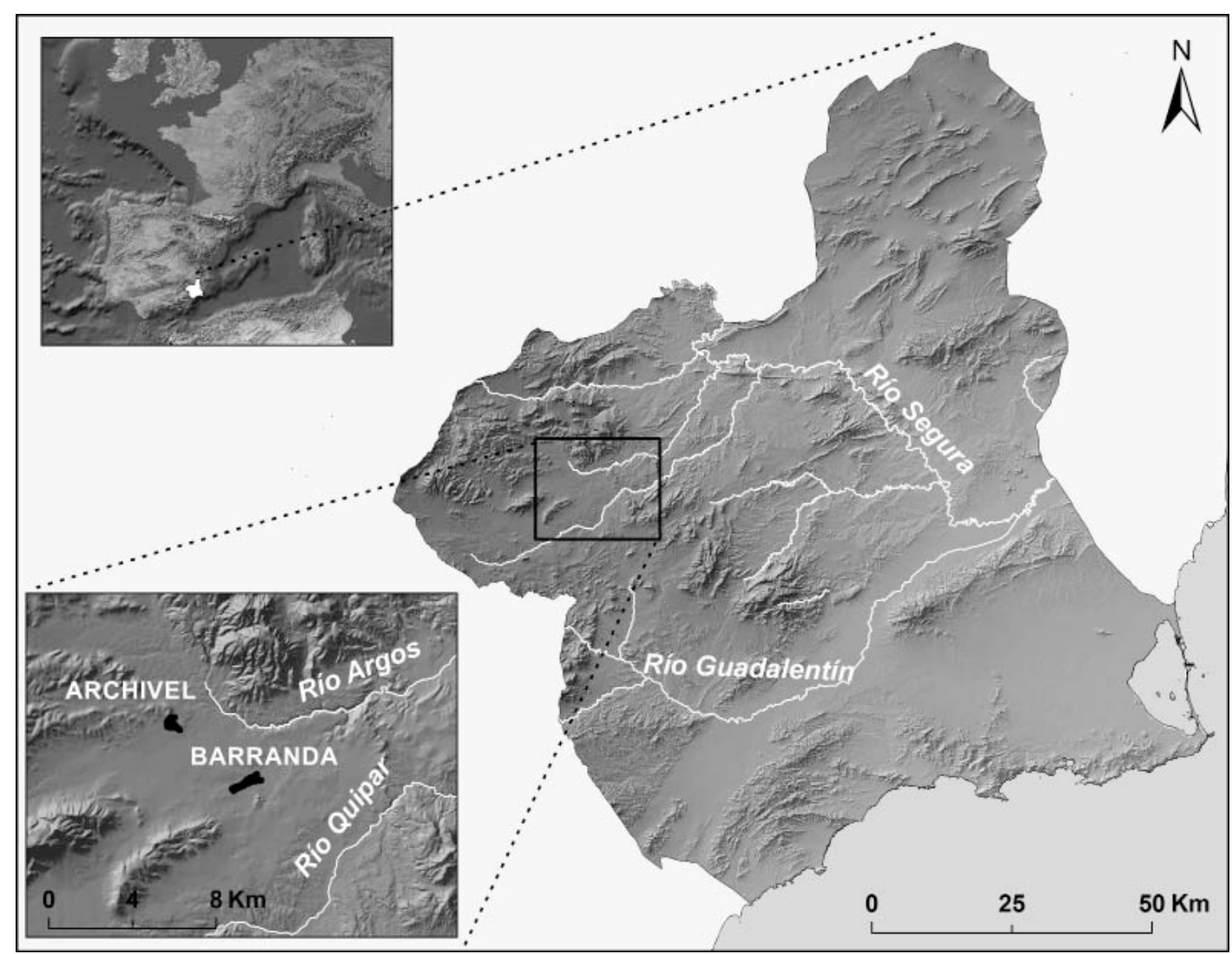

Figura 1: Localización del área de estudio en el Sureste peninsular y en la comarca del Noroeste murciano. 


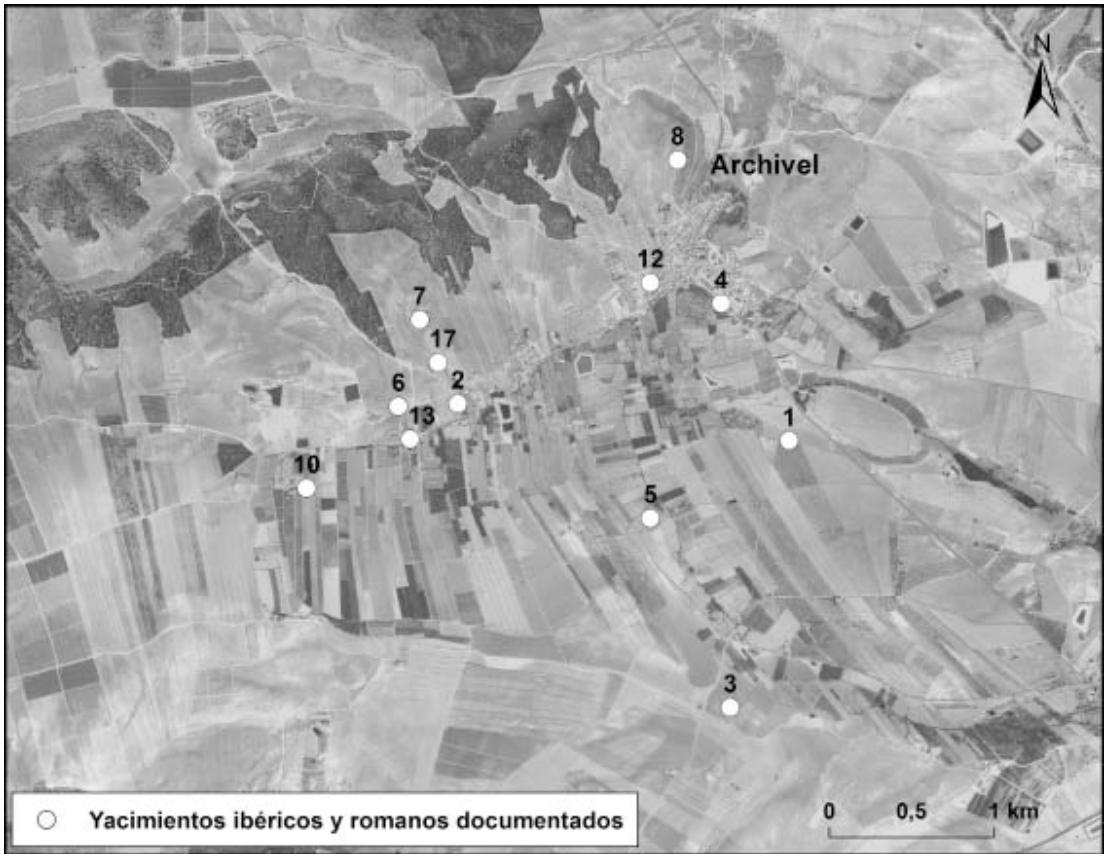

Figura 2: Vista aérea del sector de Archivel y localización de los yacimientos citados en el texto.

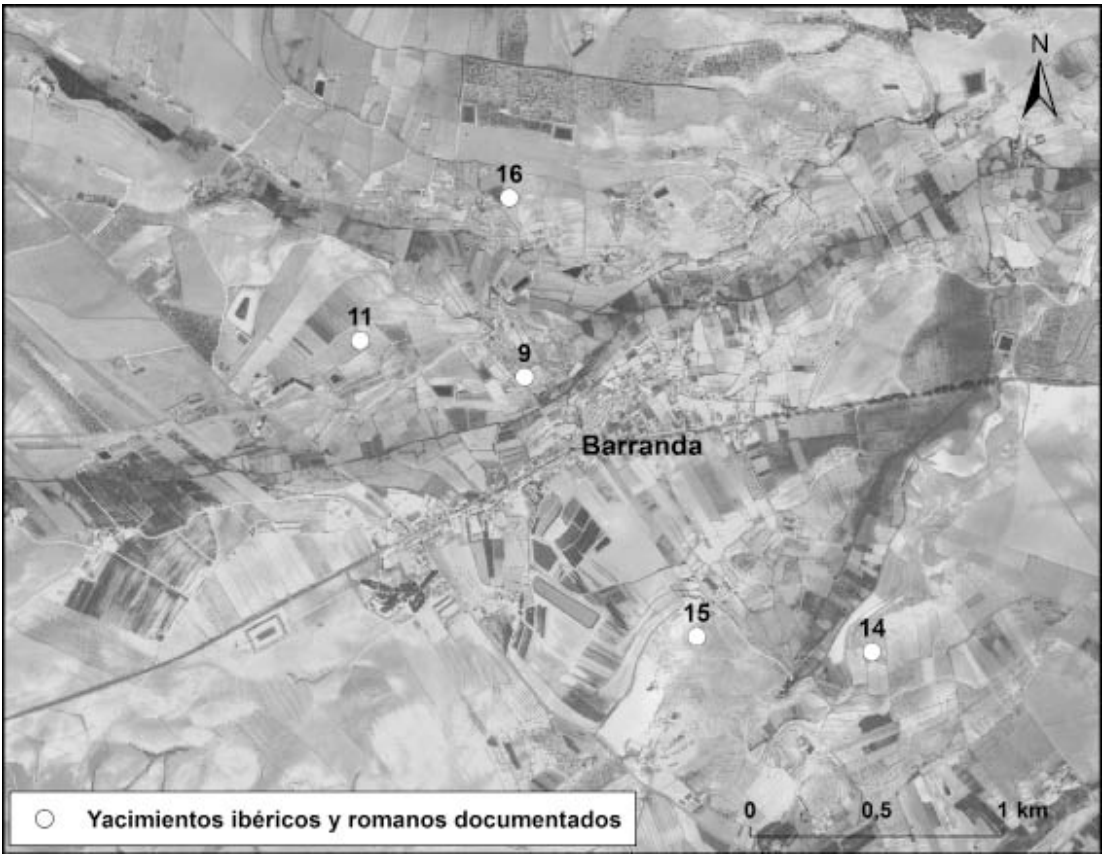

Figura 3: Vista aérea del entorno de Barranda y localización de los yacimientos analizados.

este sector a lo largo de dichas centurias, cuyo análisis es sin duda labor propia de un estudio exclusivo y más amplio que el aquí presentado.

A diferencia de otros sectores comarcales, como el vecino Estrecho de las Cuevas, la información sobre esta área es mucho más escasa, hasta el punto de que, a pesar de la importancia que están revelando algunos de los yacimientos localizados en la misma para el periodo analizado, la mayor parte de los hallazgos documentados en la zona son aun inéditos. Muchos de ellos además han sido ampliamente afectados por labores agrícolas, hecho que dificulta cada vez más el estudio de los mismos. Este trabajo ofrece así una primera aproximación de conjunto a todo este sector que permitirá conocer más de cerca el poblamiento ibérico y romano en el mismo, y enmarcar el desarrollo de yacimientos tan destacados como el citado castellum del Cerro de las Fuentes.

Los datos que ofrece la Carta Arqueológica de la Región de Murcia, fruto de las últimas prospecciones desarrolladas en la zona, han constituido sin duda un punto de partida esencial. Ha sido fundamental llevar a 
cabo una revisión de los mismos, especialmente de los relativos a aquellos yacimientos que ofrecían mas dudas en cuanto a su cronología y carácter. De este modo, se ha analizado dicha información a través del estudio de las colecciones y materiales depositados en el Museo Arqueológico Municipal de Caravaca de la Cruz ${ }^{1}$. A ellos se suman también los datos aportados por la historiografía, así como la documentación correspondiente a los últimos trabajos de campo realizados. Nuestro interés se centra sobre todo en aquellos yacimientos menos conocidos. De este modo, si bien recogemos todos los documentados en el área analizada, no nos centraremos en aquellos que han sido ya objeto de diversas publicaciones y estudios: el Cerro de las Fuentes, la Cabezuela de Barranda y El Villar. Para ellos remitimos a dichos trabajos, limitándonos aquí a señalar únicamente aquellos datos que permiten enmarcarlos en el conjunto general de los yacimientos del área.

La información recogida se presenta siguiendo un modelo basado en el esquema propuesto por Burillo, Ibáñez y Polo (1993), también utilizado en otros trabajos, y el empleado por F. Brotóns en su estudio sobre el área comarcal de la rambla de Tarragoya (Brotóns, 1995; Grau y Moratalla, 1998). Debido a las limitaciones de espacio hemos considerado apropiado adaptar y sintetizar ambos modelos, estableciendo un total de cuatro apartados que recogen los rasgos más destacados de cada yacimiento y de su entorno inmediato. El primero de ellos detalla aspectos relativos a la localización del yacimiento y a los rasgos de su entorno inmediato (características del relieve, geología, vías, condiciones de accesibilidad ${ }^{2}$, etc.). El segundo recoge los rasgos básicos de cada yacimiento como los hallazgos documentados, su tipología y su adscripción cultural. Aspectos como su extensión, aparecen recogidos en determinados casos, resultando más problemáticos en otros. En aquellos yacimientos en los que se indica responde a un cálculo aproximado de la misma atendiendo a la presencia de estructuras, a la orografía del terreno o a la dispersión de materiales en superficie. El tercer apartado se refiere a las actuaciones arqueológicas llevadas a cabo en el yacimiento y de las que proceden los materiales consultados, así como al lugar donde se han depositado éstos últimos. Finalmente un último punto está referido a la bibliografía y los estudios en los que aparece recogido dicho yacimiento.

1. Agradecemos a F. Brotóns la ayuda prestada y la información que nos ha ofrecido sobre aquellos yacimientos que se hallaban en proceso de estudio y cuyos materiales no se encontraban aun depositados en el museo durante la realización de este trabajo.

2. Se ha tenido presente la pendiente que define el entorno inmediato al yacimiento, basando su clasificación en la que ofrece la propia Carta Arqueológica regional (terrenos llanos $(<3 \%)$, sectores de pendiente suave (3-10\%), moderada (10$20 \%$ ) fuerte $(20-30 \%)$, muy fuerte $(30-50 \%)$, y escarpada (> $50 \%)$ ).
2. UNA BREVE APROXIMACIÓN AL ÁREA DE ESTUDIO: RASGOS GEOGRÁFICOS E HISTÓRICO-ARQUEOLÓGICOS

El área de estudio se extiende en el sector ocupado por las actuales poblaciones de Barranda y Archivel, ambas dentro del término municipal de Caravaca de la Cruz, en la comarca del Noroeste de la Región de Murcia (Fig. 1). Emplazada al abrigo de las Béticas, toda la comarca se sitúa en términos generales por encima de los 400 metros de altitud, oscilando el área de Archivel y Barranda entre los 800 y los 1000 metros. Atendiendo a las diferencias de altitud y climáticas entre los diversos sectores de la comarca Vicent estableció la presencia de tres 'pisos' o áreas dentro de ella. Un primer sector conformado por las zonas montañosas, otro correspondiente a los márgenes fluviales de los grandes ríos comarcales (Argos, Quípar y Moratalla) y un tercer sector constituido por las zonas de altiplanos y campiñas (Vicent, 1991, 91). Es precisamente en este último, y en los altiplanos septentrionales del término de Caravaca donde se localiza el área de estudio. Se trata de un sector comprendido entre los valles del Argos y el Quípar y enmarcado por los relieves que conforman las Sierras del Gavilán y Mojantes y la serie de lomas que se extienden desde Archivel hacia el Oeste (Brotóns y Murcia, 2008). La zona aparece además limitada al noreste por el río Argos, que discurre muy próximo a estas tierras, y al norte y noroeste por la rambla de la Higuera.

La propia disposición de los relieves y de los valles comarcales que atraviesan estas tierras ha favorecido la conexión de las mismas con el área litoral, a través del curso del Segura, y con las tierras andaluzas (LópezMondéjar, 2009a; Serrano y González, 1985, 20-22).

Esa misma disposición hace también a esta zona participe, como la cuenca del Segura, de un clima mediterráneo, si bien se observa una cierta diversidad que convierte la comarca en la zona más fría de la Región (González Ortiz, 1983, 15). La ausencia de cambios climáticos significativos en esta área del Sureste en los últimos 5000 años, resulta interesante para comprender la ocupación de estas tierras durante el periodo analizado (Albaladejo, 1991, 143-181; Gilman y Thornes, 1985).

La comarca se caracteriza en general por precipitaciones marcadas por la irregularidad y las sequías estivales. Precisamente por ello, la riqueza hídrica del sector de estudio ha favorecido históricamente una ocupación continuada y más amplia que la que se observa en otras zonas comarcales. En este sentido, desde el punto de vista de las actividades agrarias, se trata además de una de las áreas más fértiles de la comarca con suelos de elevada potencialidad agrícola. En ella se desarrollan así no sólo cultivos de secano, tradicionales en toda el área comarcal, sino también de regadío, favorecidos por la proximidad al río Argos $\mathrm{y}$, sobre todo, por la presencia de numerosas fuentes (manantial de la Higuera, manantial de Guarino, fuente de la Muralla, fuente de la Tosquilla) (Figs. 4 y 5). 


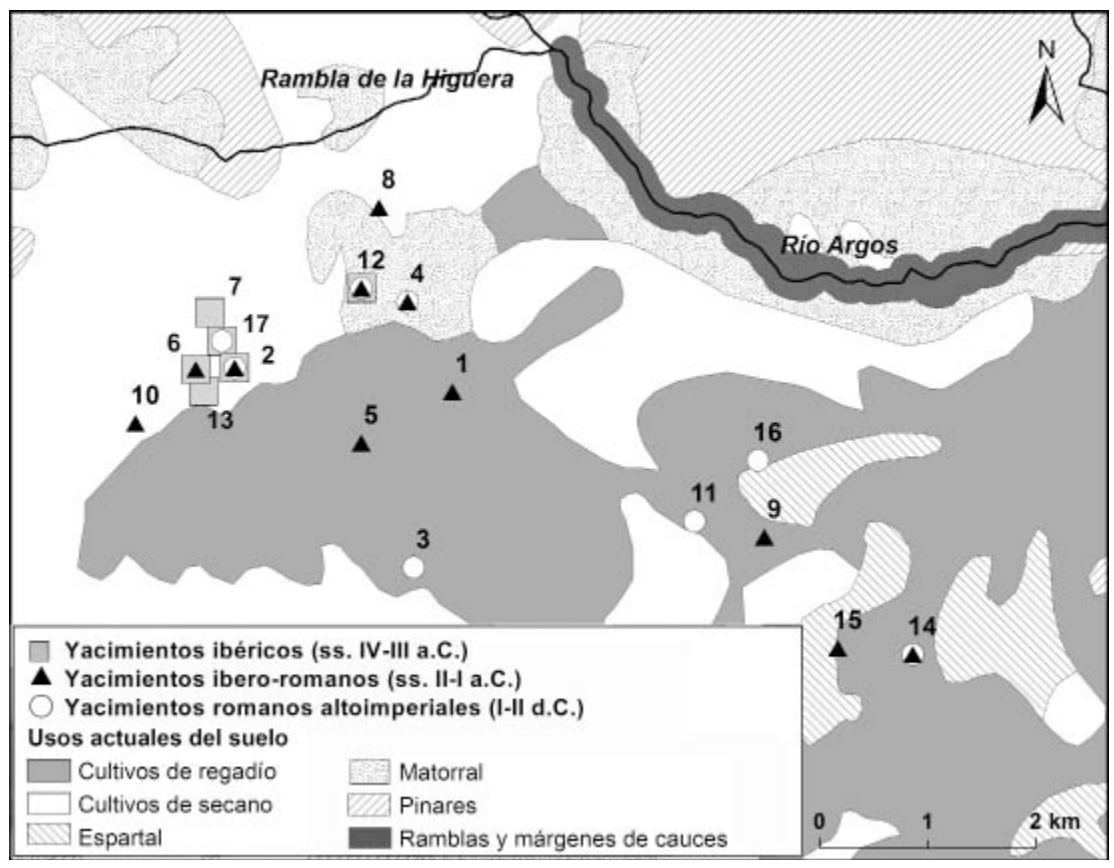

Figura 4: Distribución de los centros ibéricos, ibero-romanos y altoimperiales en la zona de estudio.

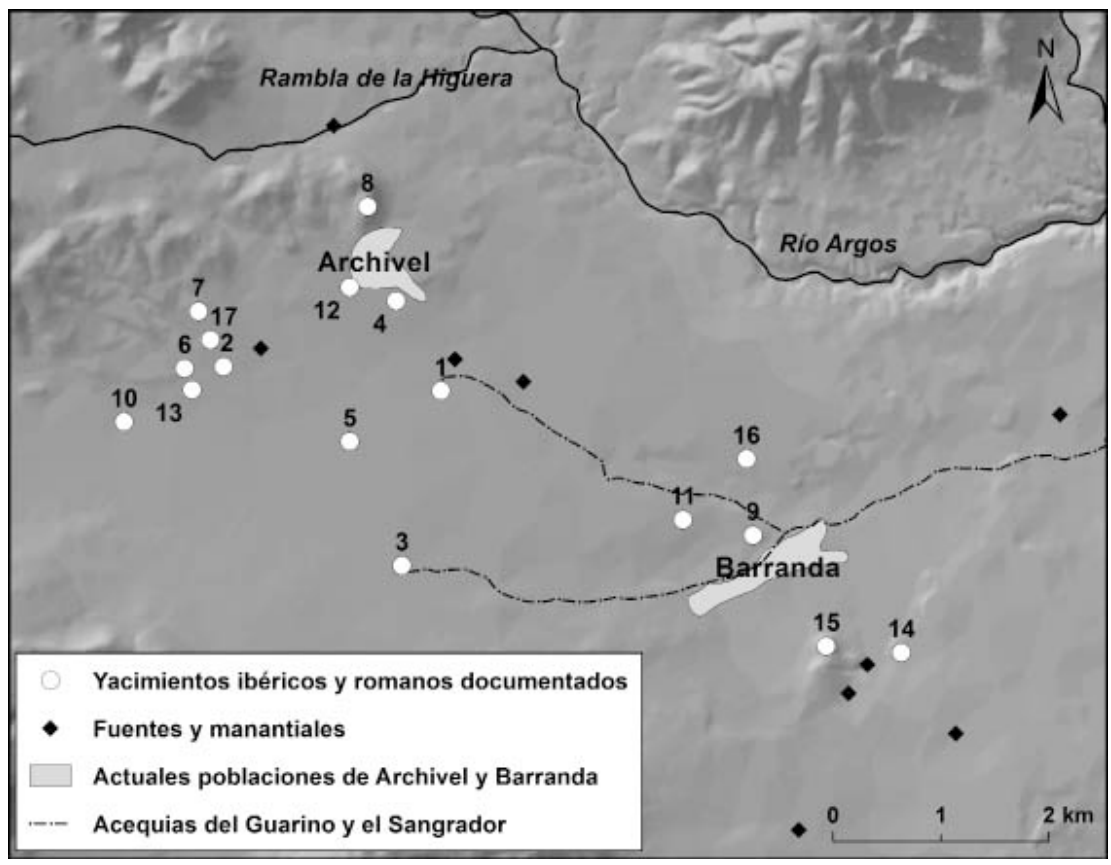

Figura 5: Distribución de los yacimientos en el área de estudio así como de los principales manantiales del entorno y de las acequias del Guarino y el Sangrador.

Para épocas previas, y concretamente para los periodos ibérico y romano, los recursos hídricos de este sector pudieron ser incluso más abundantes. En esta línea apunta la posible existencia de áreas lacustres en este ámbito comarcal, cuyo relicto lo constituían hace años los denominados Ojos de Archivel (Brotóns, 2004, 217 y 226; Brotóns y Murcia, 2008, 49-66). También interesante en este sentido es la concentración de yacimientos a lo largo del trazado de las actuales acequias del Guarino y el Sangrador (Fig. 5). Este hecho permite plantear la posible presencia en esta zona de un cauce, actualmente seco, que desde el entorno de Barranda alcanzaba el curso del Argos en las proximidades de Benablón ${ }^{3}$.

3. Se trata de una posibilidad a tener en cuenta, especialmente si tenemos presente cómo la distribución del poblamiento ha llevado en determinadas áreas itálicas, como en el valle del Po, a reconstruir la red hidrográfica de la zona en época prerromana (Patitucci, 1972, 42-43). 


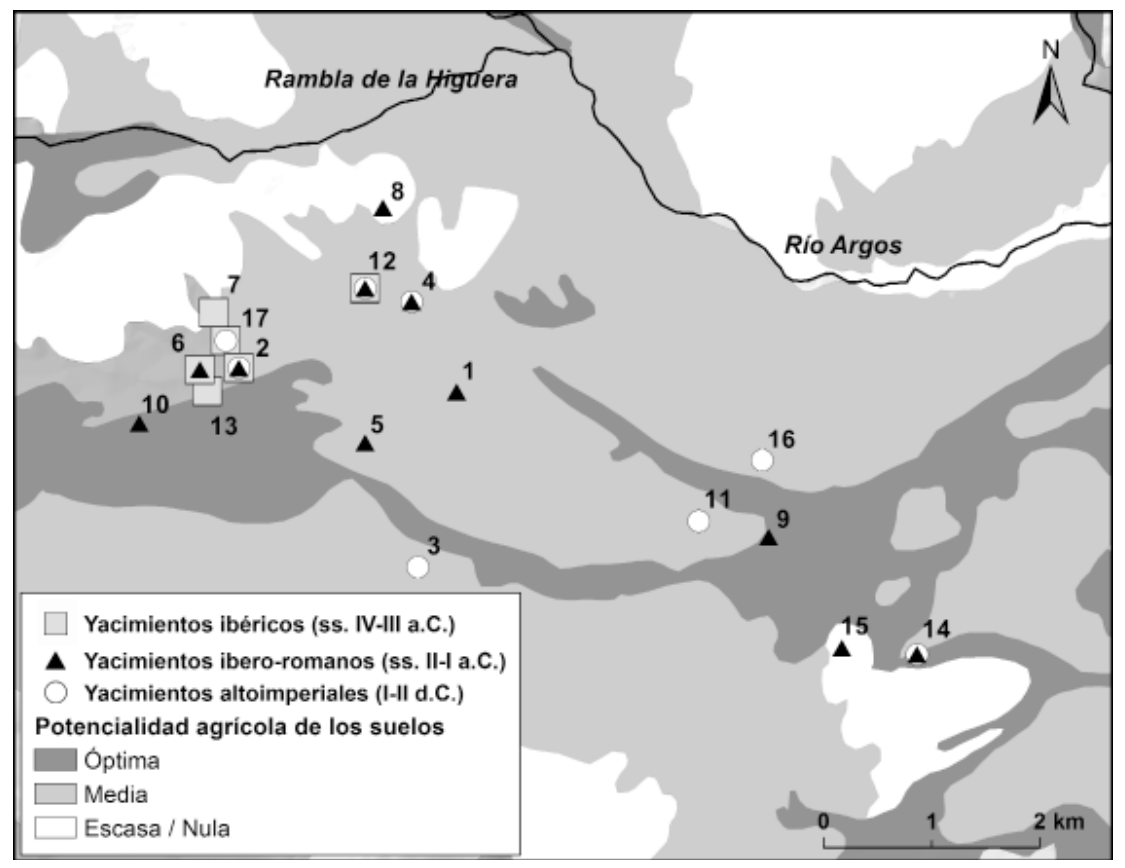

Figura 6: Localización de los yacimientos analizados y potencialidad agrícola de los suelos de su entorno.

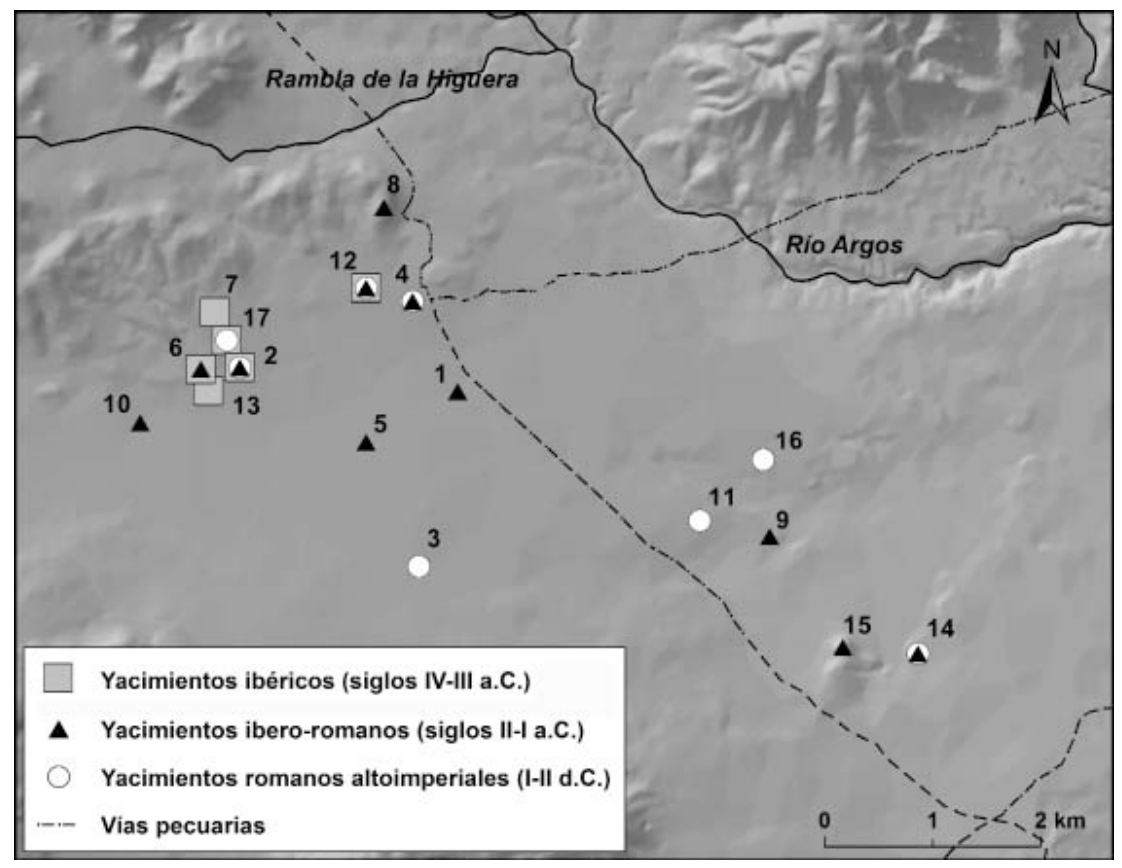

Figura 7: Localización de los yacimientos analizados y rutas ganaderas comarcales.

Junto a esa riqueza hídrica, la propia calidad de los suelos tal y como apuntamos ha sido fundamental para el desarrollo de las actividades agrarias en esta zona (Fig. 6). Aquellos sectores montañosos del entorno, de escasa o nula potencialidad agrícola, constituyen en cambio zonas aptas para las actividades ganaderas, proporcionando también interesantes posibilidades para la explotación forestal y cinegética (González, 1984, 199-204; Melgares, 1974, 45-48; Prados, Molina y Álvarez, 1991, 279-280).
Su carácter intermedio entre el área montañosa más occidental de la comarca y el valle del Quípar, ha convertido además tradicionalmente a estas tierras en una importante zona de paso de vías pecuarias (Fig. 7). La importancia de las actividades ganaderas como recurso fundamental de esta zona comarcal está además constatada ya desde época protohistórica. En este sentido, basta recordar las abundantes pesas de telar documentadas en la necrópolis de El Villar en Archivel, que, como indica Brotóns, ponen de manifiesto 
la importancia de las actividades textil y ganadera en época ibérica (Brotóns, 2008). Éstas no sólo aparecen también documentadas en algunos yacimientos andaluces próximos al área de estudio (Chapa, 1992, 322; Iborra, 2000, 81-91), sino que han sido histórica y tradicionalmente destacadas en este sector murciano. Sobre ellas encontramos referencias ya desde el XVIII en las Respuestas Generales del Catastro de Ensenada. En éstas se afirma que los textiles son las únicas producciones comercializables de la zona, tanto aquellos de origen animal, especialmente la lana, como vegetal (Pérez, 1993, 13, 40-44 y 46). También para los siglos XVIII-XIX se indica la importancia de la ganadería y de los pastos en las inmediaciones de Archivel (Madoz, 1850 (reed. 1989), 59; Pérez, 1993, 127).

Los distintos rasgos indicados han hecho de este sector del Noroeste regional un área de enorme interés para el poblamiento ya desde época prehistórica. Su ocupación continuada a lo largo de los siglos y el hecho de que se trate de una de las zonas en las que se concentra el poblamiento comarcal, reflejan su interés económico y las posibilidades que ofrece en este sentido a su población. Los trabajos de campo realizados en yacimientos como la citada necrópolis muestran su importancia ya en época ibérica, al tiempo que han dado a conocer la vinculación de esta zona con el mundo ibérico andaluz, a través de la ruta natural que representan los valles del Quípar y el Argos (Brotóns, 2009; López-Mondéjar 2009a). Del mismo modo, también los trabajos que se han desarrollado en el Cerro de las Fuentes de Archivel y en la Cabezuela de Barranda han revelado el destacado papel que dicha ruta jugó en época republicana (Brotóns y Murcia, 2008; López-Mondéjar, 2009b), mostrando de nuevo este sector como una zona de especial dinamismo e interés para aproximarnos al proceso de integración en la órbita romana del Sureste peninsular.

Todo lo indicado muestra el interés de analizar los yacimientos documentados en este sector entre los siglos IV a.C. y II d.C.

\section{CATÁLOGO DE YACIMIENTOS IBÉRICOS Y ROMANOS}

\section{1) CAsa de la Vereda}

\section{A. Localización y entorno:}

Pedanía-Diputación. Paraje: Archivel. Casa de la Vereda.

Ubicación (relieve, pendiente, accesos, altitud, hidrología y vías naturales): el yacimiento se localiza en un sector prácticamente llano, ofreciendo un acceso muy fácil y a 881 m s.n.m. La Cañada Real de Archivel discurre muy próxima al yacimiento, situándose el curso del Argos al noreste del mismo. En las proximidades se localiza también la fuente del Guarino.

Geología-suelos: Xerosoles petrocálcicos. Suelos de potencialidad agrícola media. Terreno agrícola de regadío.

\section{B. Características/Descripción del yacimiento:}

Materiales: Entre los materiales recuperados se observan algunos fragmentos de cerámica ibérica de cronología tardía, ánfora itálica y restos de molinos de mano. Adscripción cultural y cronológica: Ibero-romano (siglos II - I a.C.).

Tipología y función: Hábitat. Granja agropecuaria a juzgar por la localización del yacimiento y los materiales recuperados en el mismo.

C. Actuaciones arqueológicas y depósito: Carta Arqueológica de Caravaca de la Cruz (1998) (A. Murcia, F. Brotóns y C. García Cano). Museo Arqueológico Municipal de Caravaca de la Cruz (MAMCC 2006005 y 2006-004).

D. Bibliografía: Inédito.

\section{2) CASA de las Ánimas}

\section{A. Localización y entorno:}

Pedanía-Diputación. Paraje: Archivel. Las Casicas. Ubicación (relieve, pendiente, accesos, altitud, hidrología y vías naturales): el yacimiento se localiza en una zona de ladera baja presentando un acceso muy fácil. Se sitúa a 908 m s.n.m. y próximo al Barranco de las Casicas.

Geología-suelos: Conos de deyección y derrubios de ladera de formación cuaternaria. Suelos de potencialidad agrícola media. Arbolado agrícola.

\section{B. Características/Descripción del yacimiento:}

Materiales: Melgares (1974) señala el hallazgo de un exvoto de bronce de un animal équido de tiro en 1942 y Belda (1975) menciona la existencia en el Museo de Murcia de un vaso piriforme de vidrio. Actualmente el yacimiento se localiza en el interior del recinto de una finca particular, por lo que no ha sido posible localizar nuevos materiales. En todo caso, es posible, como indica F. Brotóns, que dichos hallazgos procedan del vecino yacimiento de las Casicas de Campo Arriba, donde cabría situar ese posible lugar de culto.

Adscripción cultural y cronológica: Ibérico y romano. Tipología y función: Indeterminado. Considerado tradicionalmente como posible santuario ibérico ofrece sin embargo muchas dudas en este sentido. Cabe pensar más bien en un establecimiento de carácter rural.

C. Actuaciones arqueológicas y depósito: Carta Arqueológica de Caravaca de la Cruz (1998) (A. Murcia, F. Brotóns y C. García Cano). Museo Arqueológico Municipal de Caravaca de la Cruz.

D. Bibliografía: Belda, 1975; González Ortiz, 1984; Li1lo, 1989 y 1999; Melgares, 1974 y 1990; Moneo, 2003.

\section{3) CASA GRAnde}

\section{A. Localización y entorno:}

Pedanía-Diputación. Paraje: Archivel. Casa Grande. Ubicación (relieve, pendiente, accesos, altitud, hidrología y vias naturales): El yacimiento se sitúa en 
un llano aluvial presentando una pendiente prácticamente llana y un acceso fácil. Está localizado a 887 m s.n.m. Junto al yacimiento discurre la acequia de Archivel y al noroeste del mismo la Cañada Real de Archivel.

Geología-suelos: Cuaternario indiferenciado. Xerosoles petrocálcicos y cambisoles cálcicos. Suelos de potencialidad agrícola media y óptima. Cultivos de secano y de regadío.

\section{B. Características/Descripción del yacimiento:}

Materiales: Entre los materiales documentados en superficie destaca la presencia de cerámicas de tradición indígena, entre ellas una tinajilla decorada con líneas y bandas rojizas y sin hombro. Aparece también terra sigillata sudgálica (una carena y un borde de la forma Drag. 27c, hispánica (posible forma Mezq. 6), africana A, africana D y africana de cocina. Asimismo, durante las prospecciones llevadas a cabo en este yacimiento se localizaron teja y ladrillo romano, un molino y restos de un fuste.

Adscripción cultural y cronológica: Romano altoimperial (desde el siglo I d.C.) y bajoimperial.

Dimensiones/Extensión: 1,5 ha.

Tipología y función: Hábitat. Granja agropecuaria.

C. Actuaciones arqueológicas y depósito: Carta Arqueológica de Caravaca de la Cruz (1998) (Prospecciones de A. Murcia, F. Brotóns y C. García Cano). Museo Arqueológico Municipal de Caravaca de la Cruz (MAMCC 1998-042).

D. Bibliografía: Inédito.

\section{4) CAsa Noguera}

\section{A. Localización y entorno:}

Pedanía-Diputación. Paraje: Archivel. Casa Noguera. Ubicación (relieve, pendiente, accesos, altitud, hidrología y vías naturales): El yacimiento se sitúa en un terreno alomado de suave pendiente y presenta un acceso muy fácil a 903 m s.n.m. La fuente de la Muralla y el manantial del Guarino se localizan en las proximidades del yacimiento, al igual que el barranco de la Loma. No podemos olvidar, además, su proximidad a todo el sector de los Ojos de Archivel. También en sus inmediaciones se localiza la confluencia entre la Cañada Real de Archivel y la Vereda del Llano de Béjar. Geología-suelos: Formación post-orogénica del Neógeno caracterizada por la presencia de calizas lacustres micríticas del Plioceno. Xerosoles petrocálcicos. Suelos de potencialidad agrícola media. Arbolado agrícola y terreno urbano.

\section{B. Características/Descripción del yacimiento:}

Materiales: Entre los materiales depositados en el museo se observa la presencia de algunos que se remontan al periodo inicial de los siglos II-I a.C., tales como un ánfora apula, comercializada generalmente entre finales de esa segunda centuria y durante la primera mitad de la siguiente, así como una Pascual 1, datada también a finales del siglo I a.C.
Del mismo modo se documentan también materiales de época imperial, tales como terra sigillata sudgálica (borde similar a la forma Drag. 27), africana A (forma Hayes 9 (Lamb. 2a)) y africana D.

Estructuras visibles: Se han constatado cabañas, pozos y silos eneolíticos, así como habitaciones y tumbas correspondientes ya a la ocupación romana de este yacimiento.

Adscripción cultural y cronológica: ibero-romano (finales del siglo II a.C.) y romano altoimperial y bajoimperial. Dimensiones/Extensión: 0,5 ha.

Tipología y función: Enterramiento y hábitat. Necrópolis y granja agropecuaria ibero-romana. Villa imperial.

C. Actuaciones arqueológicas y depósito: Carta Arqueológica de Caravaca de la Cruz (1998) (Prospecciones de A. Murcia, F. Brotóns y C. García Cano). Excavación de la cabaña $n^{0} 1$ del poblado eneolítico de Casa Noguera (1997) (F. Brotóns). Excavaciones ordinarias en el poblado (1997-1998 (L. A. García y C. Martínez) y 2001 (C. García Cano y M. J. Madrid)). Museo Arqueológico Municipal de Caravaca de la Cruz (MAMCC 1997-002).

D. Bibliografía: Álvarez y De Andrés, 2009; Brotóns, 2003, 28-30; 2004, 215-234 y 2005, 242-243; García y Madrid, 2003, 24-25; García y Martínez, 2004, 252-253.

\section{5) Casa Quemada}

\section{A. Localización y entorno:}

Pedanía-Diputación. Paraje: Archivel. Acequia de Archivel.

Ubicación (relieve, pendiente, accesos, altitud, hidrología y vías naturales): El yacimiento se localiza en un llano aluvial, con un acceso muy fácil y a $890 \mathrm{~m}$ s.n.m. El río Argos discurre al norte del yacimiento, aunque más próximos a este se localizan el barranco de la Loma, la Cañada Real de Archivel y el manantial del Guarino.

Geología-suelos: Cuaternario indiferenciado. Xerosoles petrocálcicos. Suelos de potencialidad agrícola óptima y media. Arbolado agrícola de secano.

\section{B. Características/Descripción del yacimiento:}

Materiales: Entre los materiales localizados se observa la presencia de cerámica de tradición ibérica sin decorar, cerámica de almacenamiento y un fragmento de ánfora itálica, así como también restos de teja romana. Adscripción cultural y cronológica: Ibero-romano (siglos II - I a.C.).

Dimensiones/Extensión: 0,5 ha.

Tipología y función: Hábitat. Granja agropecuaria.

C. Actuaciones arqueológicas y depósito: Carta Arqueológica de Caravaca de la Cruz (1998) (Prospecciones de A. Murcia, F. Brotóns y C. García Cano). Museo Arqueológico Municipal de Caravaca de la Cruz (MAMCC 1998-002).

D. Bibliografía: Inédito. 


\section{6) Casas del Castillico}

\section{A. Localización y entorno:}

Pedanía-Diputación. Paraje: Archivel. El Castillico. Ubicación (relieve, pendiente, accesos, altitud, hidrología y vías naturales): El asentamiento se sitúa en la parte baja de una ladera con pendiente suave y presenta un acceso fácil. Se localiza a 910 m s.n.m. La rambla de la Higuera discurre en las proximidades del yacimiento y al norte del mismo el barranco de la Loma. Geología-suelos: Calizas con sílex jurasicas del Dogger y Malm en contacto con materiales cuaternarios procedentes de conos de deyección y derrubios de ladera. Xerosoles petrocálcicos con inclusiones de litosoles y rendsinas arídicas. Suelos de potencialidad agrícola media. Arbolado agrícola.

\section{B. Características/Descripción del yacimiento:}

Materiales: Entre los materiales documentados podemos señalar, en primer lugar, la presencia de cerámica ibérica con decoración geométrica a base de bandas y líneas paralelas con pintura rojiza, y entre la que destacarían diversos fragmentos informes, un fondo anillado, fragmentos de un recipiente de almacenamiento, posiblemente una tinaja, y dos bordes rectos de tinajillas. Asimismo, encontramos también cerámica ibérica sin decorar, principalmente recipientes de almacenamiento y transporte, como un borde de labio engrosado de un ánfora (tipo A.I de Mata y Bonet (1992)), un borde similar, también con labio engrosado pero probablemente de recipiente más pequeño, quizás de una tinajilla, así como un borde recto con labio saliente (forma similar a la A.I.2.1. de Mata y Bonet). Junto a ellos, aparecen también restos de ánfora itálica y piedras de molino. Asimismo, Melgares (1974) señaló el hallazgo de tres fragmentos de dos columnas monolíticas hoy conservadas en el Museo Arqueológico Municipal de Caravaca de la Cruz, y que, sin embargo, San Nicolás ubica en el barranco de las Casicas, en el lugar conocido como Las Peñicas.

Adscripción cultural y cronológica: Ibero-romano. Probablemente corresponde a los momentos finales del mundo ibérico comarcal, aunque no podemos descartar que ya durante el Ibérico Pleno existiese algún tipo de ocupación en las proximidades de este área. En este sentido cabe señalar que es precisamente en este sector comarcal donde Melgares (1974) situó el poblado ibérico del Castillico, poniéndolo además en relación con el posible santuario de las Casicas de Campo Arriba y la necrópolis de la Ermita de San Javier.

Dimensiones/Extensión: 0,6 ha.

Tipología y función: Hábitat indeterminado. Posible granja o caserío.

C. Actuaciones arqueológicas y depósito: Carta Arqueológica de Caravaca de la Cruz (1998) (Prospecciones de A. Murcia, F. Brotóns y C. García Cano). Museo Arqueológico Municipal de Caravaca de la Cruz (MAMCC 1998-056).

D. Bibliografía: Almagro y Moneo, 2000; García, 1992; Melgares, 1974 y 1990.

\section{7) Cerro de las Canteras de Campo Arriba}

\section{A. Localización y entorno:}

Topónimo: Cerro de las Canteras de Campo Arriba (anteriormente conocido como Loma de la Cantera). Pedanía-Diputación. Paraje: Archivel. Campo Arriba. Ubicación (relieve, pendiente, accesos, altitud, hidrología y vías naturales): El yacimiento se sitúa en un cerro de pendiente moderada (10-20\%), aunque no presenta un acceso demasiado complicado. Se localiza a 937 m s.n.m. Al oeste del yacimiento discurre una rambla innominada, mientras que al noreste encontramos el barranco de la Loma y, más allá, la rambla de la Higuera. También en las proximidades se localiza la fuente de Las Noguericas y el área de los 'Ojos de Archivel'.

Geología-suelos: Xerosoles petrocálcicos con inclusiones de litosoles y rendsinas arídicas. Suelos de potencialidad agrícola media y escasa - nula. Terreno forestal. Matorrales.

\section{B. Características/Descripción del yacimiento:}

Materiales: Únicamente se documentan fragmentos de cerámica ibérica de pasta clara, que corresponderían a pequeñas pateritas y cuenquecitos de borde entrante. Se trata de materiales que encontramos también en otros santuarios del valle del Quípar, con claros paralelos en ambientes de santuario del mundo ibérico granadino (López-Mondéjar, 2010). Tampoco podemos descartar que algunos de los exvotos señalados por Melgares como procedentes del vecino yacimiento de Las Casicas pertenezcan también a este otro.

Adscripción cultural y cronológica: Ibérico (IV-III a.C.).

Tipología y función: Lugar de culto. Santuario.

C. Actuaciones arqueológicas y depósito: Carta Arqueológica de Caravaca de la Cruz (1998) (Prospecciones de A. Murcia, F. Brotóns y C. García Cano). Museo Arqueológico Municipal de Caravaca de la Cruz (MAMCC 1998-014).

D. Bibliografía: Lillo, 1986-1987, 36; López-Mondéjar, 2010; Melgares, 1990, 169-170.

\section{8) Cerro de las Fuentes de Archivel}

\section{A. Localización y entorno:}

Topónimo: Cerro de las Fuentes de Archivel (también indicado, en ocasiones, como Cerro de la Fuente de Archivel).

Pedanía-Diputación. Paraje: Archivel. Cerro de las Fuentes.

Ubicación (relieve, pendiente, accesos, altitud, hidrología y vías naturales): El yacimiento se localiza en un cerro amesetado de fuertes pendientes en las laderas este y oeste, y pendiente moderada en la ladera sur. El acceso más fácil se realiza por su parte norte, donde se sitúa el ingreso al castellum. Está emplazado a $992 \mathrm{~m}$ s.n.m. Al norte discurre la rambla de la Higuera y en sus proximidades se encuentra la fuente de la Muralla, 
localizándose el cerro en el área conocida como los 'Ojos de Archivel'. También al noreste discurre la Cañada Real de Archivel, que confluye con la vereda del Llano de Béjar al sur del yacimiento.

Geología-suelos: Litosoles con inclusión de xerosoles cálcicos. Suelos de nula potencialidad agrícola en el yacimiento y media en el entorno. Terreno forestal y matorral.

B. Características/Descripción del yacimiento:

Materiales: Entre los abundantes materiales recuperados podemos señalar la aparición de cerámica campaniense B, un plato de terra sigillata oriental de la forma Hayes 3, producción procedente del área siriopalestina datada entre finales del II a.C. y los últimos decenios del I a.C. (Brotóns y Murcia, 2008). Resulta interesante destacar que las cerámicas indígenas representan aproximadamente el $67 \%$ de los materiales recuperados (Brotóns y Murcia, 2006).

Estructuras visibles: El yacimiento aparece constituido por una estructura poligonal con una superficie de unos $2.942 \mathrm{~m}^{2}$, adaptada perfectamente a la topografía del cerro, y dos torres cuadrangulares que flanquean el ingreso al castellum (Brotóns y Murcia, 2008).

Adscripción cultural y cronológica: Establecimiento tardorrepublicano (siglo I a.C.). Reocupación medieval.

Dimensiones/Extensión: ocupa una superficie de unos $2.942 \mathrm{~m}^{2}$.

Tipología y función: Castellum. Punto de control y vigilancia.

C. Actuaciones arqueológicas y depósito: Carta Arqueológica de Caravaca de la Cruz (1998) (Prospecciones de A. Murcia, F. Brotóns y C. García Cano). Excavaciones ordinarias (2000-2011) (F. Brotóns, A. Murcia y J. García). Museo Arqueológico Municipal de Caravaca de la Cruz.

D. Bibliografía: Brotóns, 2003 y 2005; Brotóns y Murcia, 2006 y 2008; Brotóns, Murcia y García, 2004, 2005, 2006a, 2006b y 2008; González Ortiz, 1984; Lillo, 1999; López-Mondéjar, 2009b; Melgares, 1974, 101-103.

\section{9) El Altico de Barranda}

\section{A. Localización y entorno:}

Pedanía-Diputación. Paraje: Barranda. El Altico. Ubicación (relieve, pendiente, accesos, altitud, hidrología y vías naturales): El yacimiento se ubica en las proximidades de la población de Barranda, en una ladera de pendiente suave y fácil acceso a $840 \mathrm{~m}$ s.n.m. $\mathrm{Al}$ suroeste del yacimiento discurre la Cañada Real de Archivel, situándose al sureste del mismo el trazado de la acequia del Sangrador, la fuente de la Tosquilla y el nacimiento del Ojico.

Geología-suelos: Asociación de cambisoles cálcicos y fluvisoles calcáricos. Suelos de potencialidad agrícola óptima. Área agrícola de regadío.

\section{B. Características/Descripción del yacimiento:}

Materiales: Entre los materiales documentados en el museo de Caravaca de la Cruz cabe indicar la presencia de cerámica de tradición ibérica con decoración geométrica y cerámicas de almacenamiento y transporte tanto ibéricas como romanas. Entre estas últimas aparecen restos de paredes de ánfora itálica, un borde de Dressel 1B y otro de una posible Dressel 1A, que arrojan una cronología claramente tardorrepublicana para este yacimiento. La aparición asimismo de cerámica de cocina romana, terra sigillata sudgálica (un fragmento de pie con una forma similar a la Ritt. 9 (15-70 d.C.), ofrece una cronología un poco más amplia, quizás hasta los primeros momentos de ese siglo I d.C., en el que vemos desarrollarse, a unos 670 metros, el vecino asentamiento de Las Casicas de Barranda.

A todo ello cabría sumar la presencia de dos pesas de telar, una redondeada y otra con forma troncopiramidal y un ídolo del tipo Camarillas.

Adscripción cultural y cronológica: Ibero-romano (alcanzando los primeros momentos del siglo I d.C.). Se documenta también su ocupación en época prehistórica.

Tipología y función: Hábitat. Granja agropecuaria.

C. Actuaciones arqueológicas y depósito: Carta Arqueológica de Caravaca de la Cruz (1998) (Prospecciones de A. Murcia, F. Brotóns y C. García Cano). Museo Arqueológico Municipal de Caravaca de la Cruz (MAMCC 2006-017).

D. Bibliografía: Inédito.

\section{0) El Palomar}

\section{A. Localización y entorno:}

Pedanía-Diputación. Paraje: Archivel. Casas del Palomar.

Ubicación (relieve, pendiente, accesos, altitud, hidrología y vías naturales): El yacimiento se sitúa en una zona llana de muy fácil acceso y a $900 \mathrm{~m}$ s.n.m. No lejos del yacimiento, en el área de Las Noguericas así como en el paraje de Los Tarquinales, se localizan dos manantiales.

Geología-suelos: Cambisoles cálcicos. Suelos con una óptima potencialidad agrícola. Cultivos de secano.

B. Características/Descripción del yacimiento:

Materiales: Entre los materiales recuperados durante la excavación, en fase de estudio, se documenta la aparición de cerámicas que datan claramente el yacimiento en época republicana. Así, cabe destacar la aparición de restos de ánfora itálica (Lamboglia 2) y cerámica ibérica tardía lisa y con decoración geométrica, sobre todo recipientes de transporte y almacenamiento.

Adscripción cultural y cronológica: ibero-romano (III a.C.).

Tipología y función: Hábitat. Granja agropecuaria. C. Actuaciones arqueológicas y depósito: Excavación arqueológica (2007). Museo Arqueológico Municipal de Caravaca de la Cruz (MAMCC 2007).

D. Bibliografía: Inédito. 


\section{1) El Tesorico De BARRANDA}

\section{A. Localización y entorno:}

Pedanía-Diputación. Paraje: Barranda. Casas del Chorreador.

Ubicación (relieve, pendiente, accesos, altitud, hidrología y vías naturales): El yacimiento presenta un acceso muy fácil, ubicándose en una zona llana y sin pendientes a $860 \mathrm{~m}$ s.n.m. Aparece emplazado entre las acequias del Guarino y el Sangrador por las que, como indicábamos, pudo discurrir un cauce hoy seco. Al sur y suroeste del yacimiento discurre la Cañada Real de Archivel.

Geología-suelos: Rellenos aluviales. Xerosoles petrocálcicos. Suelos de potencialidad agrícola media. Arbolado agrícola.

\section{B. Características/Descripción del yacimiento:}

Materiales: Entre los materiales documentados y conservados en el museo de Caravaca de la Cruz cabe señalar la aparición de cerámicas de tradición ibérica, lisas y con decoración geométrica, cerámica romana de almacenaje y transporte (ánforas y dolia), cerámica común romana, cerámica de cocina, un borde de un vasito de imitación de paredes finas de cuerpo globular y restos de teja romana. Junto a ellos aparece también terra sigillata sudgálica (formas Drag. 18 a (15-60), Drag. 27 c (80-120)), africana A (un borde similar a la forma Hayes 6 (Lamb. 23) y un posible pie de Lamb. 18/31), africana C y D, y cerámica africana de cocina (un fondo plano estriado y dos tapaderas de las formas Ostia I, 263 y Ostia I, 261, ésta muy abundante en niveles de los siglos III - IV).

Adscripción cultural y cronológica: Romano altoimperial (I-III d.C.). Presenta también una fase de ocupación durante el periodo bajoimperial.

Dimensiones/Extensión: 1,4 ha.

Tipología y función: Indeterminado. Granja agropecuaria.

C. Actuaciones arqueológicas y depósito: Carta Arqueológica de Caravaca de la Cruz (1998) (Prospecciones de A. Murcia, F. Brotóns y C. García Cano). Museo Arqueológico Municipal de Caravaca de la Cruz (MAMCC 1998-093).

D. Bibliografía: Inédito.

\section{2) El Villar de Archivel}

\section{A. Localización y entorno:}

Pedanía-Diputación. Paraje: Archivel. El Villar.

Ubicación (relieve, pendiente, accesos, altitud, hidrología y vías naturales): Se sitúa en una ladera baja, de pendiente suave y fácil acceso a $910 \mathrm{~m}$ s.n.m. Junto al yacimiento discurre el denominado Camino de Campo Arriba y al norte la Rambla de la Higuera. Al oeste discurre la Cañada Real de Archivel y se localiza el barranco de la Loma.

Geología-suelos: Conos de deyección y derrubios de ladera del Cuaternario. Xerosoles petrocálcicos con inclusiones de litosoles y rendsinas arídicas. Suelos de potencialidad agrícola media. Arbolado agrícola.

\section{B. Características/Descripción del yacimiento:}

Materiales: Los trabajos de excavación desarrollados en la necrópolis han permitido documentar un total de 113 tumbas dispersas en dos solares, de las que 50 aparecieron arrasadas. Entre los materiales publicados por F. Brotóns cabe destacar la aparición de numerosas fusayolas y pondera, piezas completas de barniz rojo y cerámica ática del segundo cuarto del siglo IV a.C., dos jarritas de bronce del tipo Piatra Neamt intencionadamente abolladas y un simpulum de mango vertical inutilizado de la primera mitad o mediados del siglo I a.C. (Brotóns, 2009).

Estructuras visibles: Simplemente citar la existencia de diversos tipos de enterramiento, algunos con claros paralelos en el mundo ibérico granadino, entre los que destaca la presencia de empedrados tumulares y túmulos de barro y adobes (Brotóns, 2009).

Adscripción cultural y cronológica: Ibérico (desde el siglo IV a.C.), ibero-romano y altoimperial (hasta finales del I-inicios del II d.C.).

Dimensiones/Extensión: 2,46 ha.

Tipología y función: Enterramiento. Necrópolis.

C. Actuaciones arqueológicas y depósito: Carta Arqueológica de Caravaca de la Cruz (1998) (Prospecciones de A. Murcia, F. Brotóns y C. García Cano). Excavación de urgencia (2004) (F. Peñalver). Excavaciones de urgencia (2005-2007) (F. Brotóns). Museo Arqueológico Municipal de Caravaca de la Cruz.

D. Bibliografía: Brotóns, 2009; Brotóns y Ramos, 2005; Haber, 2005.

\section{3) ERmita de San Javier}

\section{A. Localización y entorno:}

Pedanía-Diputación. Paraje: Archivel. Ermita de San Javier.

Ubicación (relieve, pendiente, accesos, altitud, hidrología y vías naturales): El yacimiento se sitúa en una zona de ladera baja, con suave pendiente y un acceso muy fácil a $900 \mathrm{~m}$ s.n.m. Al noroeste del yacimiento discurre el barranco de la Loma.

Geología-suelos: Conos de deyección y derrubios de ladera de formación cuaternaria. Xerosoles petrocálcicos con inclusiones de litosoles y rendsinas arídicas. Suelos de potencialidad agrícola óptima y media. Cultivos de regadío. El yacimiento está parcialmente ocupado por el caserío y la Ermita de San Javier.

\section{B. Características/Descripción del yacimiento:}

Materiales: Tenemos noticias del año 1949, y con motivo de una nivelación del terreno, del hallazgo de una urna de orejetas y de diversas urnas de incineración, todas ellas según Melgares destruidas, salvo una que se conservaba en una colección particular (Melgares, 1990, 165-166). A ellas añade también Melgares la aparición de un exvoto de équido que más tarde señala como procedente del vecino yacimiento de la Casa de 
las Ánimas (Melgares, 1974, 13 y 145-146, y 1990). Asimismo, otros restos documentados parecen asociarse a la presencia de una necrópolis de incineración en esta área.

Adscripción cultural y cronológica: Ibérica.

Dimensiones/Extensión: 0,5 ha.

Tipología y función: Enterramiento. Necrópolis.

C. Actuaciones arqueológicas y depósito: Carta Arqueológica de Caravaca de la Cruz

(1998) (Prospecciones de A. Murcia, F. Brotóns y C. García Cano). Museo Arqueológico Municipal de Caravaca de la Cruz. Museo Arqueológico Provincial de Murcia.

D. Bibliografía: Melgares, 1974, 13 y 145-146, y 1990 .

\section{4) Fuente de Las TosQuiLlas}

\section{A. Localización y entorno:}

Topónimo: Fuente de Las Tosquillas o Las Tosquillas. Pedanía-Diputación. Paraje: Barranda. Fuente de la Tosquilla.

Ubicación (relieve, pendiente, accesos, altitud, hidrología y vías naturales): Se sitúa en una loma de pendiente suave y acceso fácil a $834 \mathrm{~m}$ s.n.m. Fuente de la Tosquilla y nacimiento del Ojico al suroeste del yacimiento.

Geología-suelos: Margas del Cretácico Superior. Cambisoles cálcicos con inclusión de fluvisoles. Suelos de potencialidad agrícola óptima y media. Arbolado agrícola.

\section{B. Características/Descripción del yacimiento:}

Materiales: Entre los materiales aparece cerámica común romana y cerámica ibérica tardía con decoración pintada y lisa (bordes moldurados, rectos, un borde con forma de cabeza de ánade y un borde subtriangular similar a la forma A.II.10 de Mata y Bonet). Asimismo se documenta cerámica de almacenamiento romana, entre ella restos de ánfora itálica, y un fragmento que parece corresponder a una imitación de un mortero del tipo 'dediles' de época republicana. En la Carta Arqueológica se señala también la aparición de cerámicas altoimperiales (terra sigillata sudgálica y africana A) que sin embargo, no hemos observado entre los materiales depositados en el museo.

Adscripción cultural y cronológica: Ibero-romano. No podemos descartar su continuidad en época imperial si tenemos presentes las noticias sobre la aparición de cerámicas altoimperiales en el yacimiento. A pesar de ello no hemos documentado entre los materiales consultados ninguno que ofrezca dicha cronología.

Dimensiones/Extensión: amplia dispersión de materiales en un área próxima a las 3 ha.

Tipología y función: Hábitat. Granja agropecuaria.

C. Actuaciones arqueológicas y depósito: Carta Arqueológica de Caravaca de la Cruz (1998) (Prospecciones de A. Murcia, F. Brotóns y C. García Cano).
Museo Arqueológico Municipal de Caravaca de la Cruz (MAMCC 1998 y 1998-037).

D. Bibliografía: Inédito.

\section{5) La CABezuela de Barranda}

\section{A. Localización y entorno:}

Pedanía-Diputación. Paraje: Barranda. Cerros de la Cabezuela.

Ubicación (relieve, pendiente, accesos, altitud, hidrología y vías naturales): Pequeño cerro con fuertes pendientes en su ladera norte y con un acceso más fácil por el sector más meridional situado a 879 m s.n.m. Al sur del yacimiento discurre la Cañada Real de Archivel, mientras que también en sus proximidades se localizan la fuente de la Tosquilla y el nacimiento del Ojico.

Geología-suelos: Litosoles con inclusiones de xerosoles cálcicos. Suelos de escasa-nula potencialidad agrícola en el sector donde se ubica el yacimiento y de potencialidad óptima en el entorno. Cultivos de regadío y terreno forestal (matorral y esparto).

\section{B. Características/Descripción del yacimiento:}

Materiales: Al igual que en el Cerro de Las Fuentes de Archivel, también los materiales ibéricos son claramente predominantes en este yacimiento. Aun así se documentan también numerosas importaciones itálicas, tanto de cerámica fina como de almacenaje y cocina (Brotóns y Murcia, 2008).

Estructuras visibles: Se ha documentado una estructura en forma de polígono irregular con una superficie aproximada de unos $860 \mathrm{~m}^{2}$ a la que se anexa otra estructura menor que sobresale en el ángulo occidental con unas dimensiones de 13,4 m. x 5,38 m., con un pavimento de opus signinum (Brotóns y Murcia, 2008). Adscripción cultural y cronológica: Tardorrepublicano (siglo I a.C.). Aprovechamiento agrícola de la cumbre en época medieval.

Dimensiones/Extensión: $930 \mathrm{~m}^{2}$.

Tipología y función: Castellum. Punto de control, vigilancia y posiblemente también de aprovisionamiento.

C. Actuaciones arqueológicas y depósito: Carta Arqueológica de Caravaca de la Cruz (1998) (Prospecciones de A. Murcia, F. Brotóns y C. García Cano). Realización de sondeos estratigráficos (F. Brotóns y A. Murcia). Museo Arqueológico Municipal de Caravaca de la Cruz.

D. Bibliografía: Brotóns y Murcia, 2008; Brotóns, Murcia y García, 2008; López-Mondéjar, 2009b.

\section{6) LAS CASICAS de BARRANDA}

\section{A. Localización y entorno:}

Pedanía-Diputación. Paraje: Barranda. Las Casicas. Ubicación (relieve, pendiente, accesos, altitud, hidrología y vías naturales): El yacimiento se sitúa en una zona prácticamente llana, de escasa pendiente, presentando un acceso muy fácil a $850 \mathrm{~m}$ s.n.m. Al 
suroeste del yacimiento discurre la Cañada Real de Archivel.

Geología-suelos: Xerosoles petrocálcicos. Suelos de potencialidad agrícola media. Terreno agrícola de regadío.

\section{B. Características/Descripción del yacimiento:}

Materiales: Entre los escasos materiales recuperados destaca la presencia de terra sigillata sudgálica y de terra sigillata africana (mal conservada, posiblemente africana A).

Adscripción cultural y cronológica: Romano altoimperial.

Tipología y función: Indeterminado. Posiblemente se trate de una granja agropecuaria a juzgar por los rasgos que definen su localización y su entorno más inmediato así como por los materiales documentados. C. Actuaciones arqueológicas y depósito: Prospección (2004). Museo Arqueológico Municipal de Caravaca de la Cruz (MAMCC 2004).

D. Bibliografía: Inédito.

\section{7) Las Casicas de CAmpo Arriba}

\section{A. Localización y entorno:}

Pedanía-Diputación. Paraje: Archivel. Las Casicas. Ubicación (relieve, pendiente, accesos, altitud, hidrología y vías naturales): El yacimiento se sitúa en una zona de ladera baja, con suave pendiente y fácil acceso a 919 m s.n.m. Pequeño barranco procedente de Las Piedras del Lagarto en las proximidades del yacimiento.

Geología-suelos: Conos de deyección y derrubios de ladera de formación cuaternaria. Xerosoles petrocálcicos con inclusiones de litosoles y rendsinas arídicas. Suelos de potencialidad agrícola media. Cultivos de secano (arbolado agrícola).

\section{B. Características/Descripción del yacimiento:}

Materiales: Entre los materiales de época ibérica destaca el claro predominio de recipientes de pequeño tamaño, en su mayoría platos, tanto lisos como con decoración geométrica, que presentan bordes salientes, sin diferenciar (escudillas), en ala plana, así como exvasados (similares al tipo III.8.1.2.9. de Mata y Bonet (1992)), y también fondos anillados, de base cóncava o de base plana.

Del yacimiento romano altoimperial se ha recuperado cerámica común romana (tinajillas, un olpe y pequeños vasitos), cerámica de cocina, cerámica de tradición ibérica con decoración geométrica, terra sigillata sudgálica (un plato de pared vertical ligeramente exvasada, similar a la forma Hayes 5 (Drag. 2/21) (10-50 d.C.)) y terra sigillata africana A (posible borde de la forma Hayes $3 \mathrm{~A}$ de mediados del II d.C.). También se han documentado restos de teja romana y San Nicolás (1984) sitúa en esta zona el hallazgo de tres fragmentos de dos columnas monolíticas romanas, que Melgares (1974) localiza en las Casas del Castillico.
Adscripción cultural y cronológica: Ibérico y romano altoimperial.

Dimensiones/Extensión: 0,19 ha.

Tipología y función: Si bien ha sido interpretado como un posible lugar de culto ibérico, es más probable, como indica F. Brotóns, que se trate de un área de necrópolis en época ibérica. Granja agropecuaria de época romana a juzgar por los materiales recuperados, si bien no podemos descartar un hábitat de mayor entidad si atendemos a los hallazgos recogidos por San Nicolás (1984).

C. Actuaciones arqueológicas y depósito: Carta Arqueológica de Caravaca de la Cruz (1998) (Prospecciones de A. Murcia, F. Brotóns y C. García Cano). Museo Arqueológico Municipal de Caravaca de la Cruz (MAMCC 1997-005 y 1998-006).

D. Bibliografía: Melgares, 1974; San Nicolás, 1984.

4. HACIA UNA VISIÓN DIACRÓNICA DE LOS DATOS: EL POBLAMIENTO IBÉRICO Y ROMANO EN LOS ALTIPLANOS DEL NOROESTE MURCIANO.

Tras todo lo indicado podemos establecer una breve síntesis de la dinámica poblacional en el área de estudio entre los siglos IV a.C.-II d.C. así como de los rasgos que definen el poblamiento ibérico y romano en esta área regional murciana.

La ocupación de este sector, y especialmente del área de Archivel, se remonta ya a época prehistórica, favorecida por los ricos recursos que ofreció a las comunidades humanas asentadas en él. A la fertilidad de los suelos se suma, como hemos indicado, la riqueza faunística atraída por la abundancia de agua en la zona, así como una posición estratégica que propició las comunicaciones con Andalucía y levante (Brotons, 2004, 226). Reflejo de las mismas, y especialmente de las relaciones con el ámbito andaluz granadino son los paralelos que ya desde época prehistórica ofrecen yacimientos como el de Casa Noguera así como también, durante el periodo ibérico, la propia necrópolis del Villar de Archivel (Brotóns, 2009) o los santuarios documentados en todo este sector comarcal (LópezMondéjar, 2010).

No tenemos documentado ningún yacimiento que podamos encuadrar en los siglos VI-V a.C. en este sector, hecho que, sin embargo, no resulta extraño teniendo en cuenta el escaso poblamiento localizado a lo largo de los valles del Argos y el Quípar en estos momentos. Únicamente el oppidum localizado en Los Villares, en las proximidades de la pedanía de La Encarnación, aporta datos para dicho periodo en la zona.

Es a partir del siglo IV a.C., con el inicio de la ocupación del oppidum de Los Villaricos y el abandono de Los Villares, cuando se observa un destacado cambio en el poblamiento ibérico de ambos valles. Surge a partir de entonces un importante número de asentamientos que, además, se localizarán de forma especial 
no sólo junto a los cauces de los ríos, sino sobre todo en el sector de los altiplanos localizado al oeste de La Encarnación y que constituye el área de estudio.

De este modo, es precisamente en el entorno de Archivel donde, desde el siglo IV a.C., vemos concentrarse ya el poblamiento y donde se sitúan todos los yacimientos ibéricos señalados en el apartado anterior (Fig. 2). Aparecen emplazados en tierras aptas para el desarrollo de las actividades agrícolas, si bien la ganadería debió desempeñar también un papel destacado en su economía. En este sentido es interesante recordar, como señalábamos al inicio, el elevado número de pesas de telar documentadas en las tumbas excavadas en la necrópolis del Villar, incluso en aquellas masculinas, así como las tijeras de podar halladas también en dicho yacimiento (Brotóns, 2009). Todo ello delata, junto a los rasgos geográficos e históricos indicados anteriormente, una población en la que la ganadería y las actividades relacionadas con ella, como la textil, adquirieron también una especial importancia.

El poblamiento que se desarrolla a lo largo de los valles del Argos y el Quípar entre los siglos IVIII a.C. revela un modelo de ocupación jerarquizado, a la cabeza del cual se situaría el oppidum localizado en Los Villaricos. No se documenta ningún otro centro ibérico de especial importancia que podamos situar al nivel de dicho oppidum, observándose en cambio toda una serie de centros rurales de carácter secundario y situados bajo el control de aquel. Dichos centros no ofrecen tampoco una entidad homogénea, documentándose tanto aldeas o pequeños poblados, como núcleos menores que podríamos definir como pequeñas granjas o caseríos. Si bien estos últimos no se documentan en el área de estudio, distribuyéndose por otros sectores de la comarca, sí lo hacen los primeros. Entre ellos se encuentra el núcleo asociado a la necrópolis del Villar. Los datos aportados por el área funeraria apuntan a un centro en el que se observa la presencia de personajes de cierta riqueza y que debieron poseer un estatus privilegiado dentro de la comunidad, como muestra la jerarquía de tumbas documentadas (Brotóns, 2008). No debió tratarse en ningún momento de un centro equiparable al localizado en Los Villaricos, sino de uno de esos poblados secundarios vinculado a la explotación agrícola del entorno y en el que también alcanzaron cierto desarrollo las actividades artesanales. Entre estas aldeas quedarían englobados otros núcleos comarcales como el localizado en la Loma de la Casa Nueva cuya necrópolis muestra también una cierta riqueza económica (importaciones áticas, joyas de oro).

El poblamiento aparece así concentrado en las inmediaciones de Archivel hasta finales del III a.C., momento en el que la presencia romana en las costas del Sureste supondrá cambios en toda esta área peninsular que se dejarán sentir también en el interior regional murciano.

De este modo, hay que esperar a finales del III a.C. e inicios del II a.C. para observar una expansión del poblamiento hacia el sector ocupado actualmente por la población de Barranda (Fig. 3). En estas centurias surgen nuevos asentamientos rurales, como los localizados en la Fuente de las Tosquillas, Casa de la Vereda y Casa Quemada. Se trata en todos los casos de pequeñas granjas agropecuarias de escasa extensión y situadas en zonas llanas y en lomas de escasa pendiente que favorecen la explotación de las tierras del entorno. Todas se localizan además próximas a alguno de los manantiales de este sector, así como a las acequias del Guarino y el Sangrador por las que, como apuntamos, pudo discurrir en aquella época un curso de agua hoy seco.

La mayor parte de los centros siguen ocupando sin embargo el sector de Archivel, estableciéndose próximos a la vía natural de comunicación que alcanza las tierras de Nerpio a través de esta zona y a la ruta ganadera que siguiendo el mismo trazado se adentra hasta el sector serrano más occidental de la comarca (Fig. 7).

El poblamiento de estas centurias previas al cambio de Era (finales del III-mediados I a.C.) aparece así definido por esas granjas agropecuarias que marcarán el inicio del cambio en el modelo de ocupación ibérico en toda la comarca, extendiéndose por sectores en los que hasta el momento no se documentaba la presencia de un poblamiento estable. Junto a ellos, el oppidum de Los Villaricos continuará a la cabeza del poblamiento de ambos valles, controlando esas rutas de comunicación y dominando todo el territorio con la ayuda del santuario localizado en La Encarnación, que experimenta ahora una destacada transformación edilicia (Ramallo, 1991). La construcción de dos templos de estilo itálico en el cerro, donde se localizaba el santuario ibérico, convierte así a dicho lugar de culto en un punto esencial en el paisaje de este sector.

El análisis de los yacimientos documentados en el siglo I a.C. en el área de estudio muestra de nuevo un cambio en el poblamiento. El panorama se transforma a mediados de dicha centuria como consecuencia del traslado a este sector del Sureste peninsular de los conflictos civiles entre los partidarios de César y los de Pompeyo. Reflejo de ello es la instalación de dos castella localizados en el Cerro de las Fuentes de Archivel y en el vecino cerro de La Cabezuela de Barranda. La situación de inestabilidad que caracteriza estos territorios y el establecimiento de ambos castella da lugar a la desaparición de la mayor parte de esas granjas agropecuarias que veíamos surgir desde finales del III a.C. El oppidum de Los Villaricos continuará en cambio ocupado, si bien los restos materiales documentados en el mismo reflejan también las consecuencias de dichos conflictos en los que éste núcleo debió verse sin duda involucrado por su situación estratégica y su papel territorial (López-Mondéjar, 2009b: 109).

En este sentido, y entre los escasos yacimientos de los que disponemos de datos de excavación para el siglo I a.C., es la necrópolis de Casa Noguera la que mejor muestra las consecuencias de dichos conflictos. En ella se ha documentado un nivel de abandono en el 
siglo I a.C. que cabe poner claramente en relación con aquellos (Brotóns, 2003, 28).

De este modo es ya a finales del I a.C. y muy especialmente a partir del siglo I d.C., una vez finalizadas las luchas civiles, cuando estos territorios del Noroeste murciano experimentarán un nuevo periodo de desarrollo poblacional. A partir del cambio de Era, y tras la desaparición de la mayor parte de esas granjas y establecimientos rurales ibero-romanos a finales de la centuria anterior, surgen de nuevo numerosos centros que se extienden ya por toda el área de estudio. En ella, únicamente los yacimientos localizados en el Villar de Archivel y Casa Noguera continúan ocupados desde el periodo anterior.

El desarrollo poblacional que se produce a partir del I d.C. en las proximidades de Archivel ha sido puesto en conexión precisamente con el final de la ocupación del vecino castellum del Cerro de las Fuentes. Se ha apuntado así al posible traslado de sus ocupantes a zonas llanas, estableciéndose en pequeños asentamientos rurales en el entorno de aquel (García y Martínez, 2004, 241-244). Lo cierto es que si bien se observa en el castellum un claro predominio de las cerámicas ibéricas que podría llevar a pensar en la presencia de contingentes indígenas, no podemos olvidar que se trata de un momento en el que no existe aun una infraestructura estatal ni militar en este territorio. Como explican sus excavadores el suministro dependió así de manufacturas y productos locales, de ahí que la presencia y predominio de esas producciones ibéricas frente a las itálicas (Brotóns y Murcia, 2008, 49-66) no tiene por qué ser interpretada como resultado de una ocupación mayoritariamente indígena de dicho castellum.

En general los nuevos centros altoimperiales presentan un patrón de asentamiento cuyos rasgos ofrecen muchos paralelos con el de las granjas agropecuarias del periodo anterior y sólo en algún caso podemos hablar de villae. Ubicados también en zonas llanas, presentan un carácter marcadamente rural y vinculado a la explotación del territorio. Todos ellos se sitúan en tierras de elevada potencialidad agrícola y próximos a las fuentes y manantiales de esta área, así como a ese posible cauce seco al que nos referíamos también para los centros ibero-romanos (Fig. 5). Asimismo, su proximidad a las rutas ganaderas que discurren por este sector y que enlazan con los sectores serranos del noroeste regional lleva a pensar en la importancia que continuó teniendo la ganadería en dichos asentamientos (Fig. 7).

A diferencia sin embargo del periodo anterior, aparecen en estos momentos establecimientos de diversa categoría que permiten plantear una reorganización de la explotación en todo el sector. Así, se observa la existencia de pequeños establecimientos agropecuarios, como que los documentados en la Casa de las Ánimas, Casa Grande, las Casicas de Barranda o El Tesorico, frente a otros de carácter distinto. Entre éstos destaca el localizado en Casa Noguera, definido como una villa de la que se ha recuperado parte de la pars rustica (García y Madrid, 2003, 24-25; García y Martínez, 2004, 241-244). Si bien será en época bajoimperial cuando dicho centro alcance un mayor desarrollo, como han reflejado los trabajos de campo realizados en el mismo, está claro que también en estos momentos tuvo un carácter distinto al de esos otros asentamientos. Más complicado resulta, por el momento, plantear la posible vinculación a dicha villa de los centros documentados en su entorno, ya que por el momento se desconocen las dimensiones reales del asentamiento en este periodo así como su organización.

Otro centro que refleja también esa reorganización en la explotación de estos territorios en época altoimperial es el localizado en la Fuente de la Teja. En él, emplazado junto al valle del Quípar y muy próximo al área de estudio, se ha documentado una instalación de carácter oleícola con diversas estructuras destinadas a actividades relacionadas con la preparación del aceite (prensado, decantación) así como al alojamiento de los trabajadores correspondientes (Murcia y Brotóns, 2006).

En general, los yacimientos analizados nos ofrecen una imagen global de la dinámica poblacional en el sector estudiado y reflejan, enmarcados en el paisaje ibérico y romano de estos territorios interiores regionales, el dinamismo de esta área murciana durante las centurias analizadas. En cualquier caso, somos conscientes de que nuevos trabajos de campo podrán aportar más información en esta línea, que sin duda permitirá revisar y completar el catálogo de yacimientos presentado así como muchos de los planteamientos indicados.

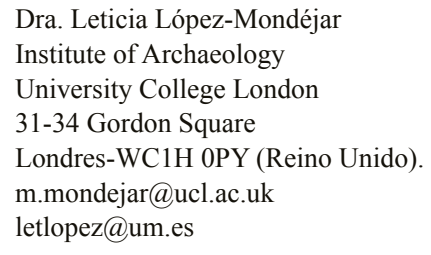

\section{BIBLIOGRAFÍA}

ALBALADEJO, J., 1991: «Edafología», en P. LÓPEZ: $E l$ cambio cultural del IV al II milenios a.C. en la comarca Noroeste de Murcia, 1, 143-181, Madrid.

ALMAGRO-GORBEA, M. y MONEO, T., 2000: Santuarios urbanos en el mundo ibérico, Madrid.

ÁLVAREZ, D. y DE ANDRÉS, M., 2009: «Intervención arqueológica en el yacimiento de Casa Noguera (Archivel, Caravaca de la Cruz, Murcia). La reutilización de un espacio calcolítico», Espacio, Tiempo y Forma, Serie I, Nueva época. Prehistoria y Arqueología, t. 2, 119-126.

BELDA, C., 1975: El proceso de romanización de la provincia de Murcia, Murcia.

BROTÓNS, F., 1995: «El poblamiento romano en el valle alto del Quípar (Rambla de Tarragoya), Caravaca de la Cruz (Murcia)», en J.M. NOGUERA (Coord.), 
Poblamiento rural romano en el Sureste de Hispania, 247-274, Murcia.

BROTÓNS, F., 2003: «Excavaciones arqueológicas en Casa Noguera de Archivel (Caravaca de la Cruz). Solar en calle Virgen de la Esperanza y calle Casa Noguera», XIV Jornadas de Patrimonio histórico y Arqueología de la Región de Murcia (Murcia, del 17 al 21 de noviembre de 2003), 28-30, Murcia.

BROTÓNS, F., 2004: «El poblado calcolítico de Casa Noguera de Archivel. Excavaciones urgentes durante 1997 en Calle Reyes - Calle Casa Noguera», Memorias de Arqueología, 12 (1997), 215-234.

BROTÓNS, F., 2005: «Excavación de urgencia en el paraje de Casa Noguera de Archivel. Solar a calle Gran Vía y calle Reyes», Actas de las XVI Jornadas de Patrimonio Histórico de la Región de Murcia, 242-243, Murcia.

BROTÓNS, F., 2008: «La necrópolis tumular ibérica de «El Villar de Archivel» (Caravaca de la Cruz-Murcia)», Actas del I Congreso Internacional de Arqueología Ibérica Bastetana (Baza, 7 - 10 mayo de 2008), 23-42, Madrid.

BROTÓNS, F. y LÓPEZ-MONDÉJAR, L., 2009: «Poblamiento rural romano en el Noroeste», en J.M. NOGUERA(Coord.), Poblamiento rural romano en el Sureste de Hispania 15 años después, 413-438, Murcia.

BROTÓNS, F. y MURCIA, A.J., 2006: «El castellum tardorrepublicano del Cerro de las Fuentes de Archivel (Caravaca de la Cruz, Murcia). Estudio preliminar», en A. MORILLO (Coord.), Arqueología militar romana en Hispania. Producción y abastecimiento en el ámbito militar, 639-653, León.

BROTÓNS, F. y MURCIA, A.J., 2008: «Los castella tardorrepublicanos de la cuenca alta de los ríos Argos y Quípar (Caravaca, Murcia). Aproximación arqueológica e histórica», en M.P. GARCÍA, A. MOSTALAC y A. JIMÉNEZ (Eds.), Del imperivm de Pompeyo a la avctoritas de Augusto. Anejos de Archivo Español de Arqueología, XLVII, 49-66, Madrid.

BROTÓNS, F. y RAMOS, F., 2005: «Informe de la excavación arqueológica urgente en la necrópolis ibérica de El Villar de Archivel. Solar en calle Poli s/n», Actas de las XVI Jornadas de Patrimonio Histórico de la Región de Murcia, 259, Murcia.

BROTÓNS, F., MUÑOZ, A. y GARCÍA, J., 2004: «El Cerro de las Fuentes de Archivel (Caravaca de la Cruz). Tercera campaña de excavaciones arqueológicas y de consolidación de estructuras», Resumen de las XV Jornadas de Patrimonio histórico y Arqueología de la Región de Murcia (Murcia, del 24 de noviembre al 2 de diciembre de 2004), 78-80, Murcia.

BROTÓNS, F., MUÑOZ, A. y GARCÍA, J., 2005: «El Cerro de las Fuentes de Archivel (Caravaca de la Cruz). Cuarta campaña de excavaciones arqueológicas», Actas de las XVI Jornadas de Patrimonio Histórico de la Región de Murcia, 257-258, Murcia.

BROTÓNS, F., MUÑOZ, A. y GARCÍA, J., 2006a: «Informe de los trabajos de excavación arqueológica y Labores de consolidación de estructuras en el Cerro de las Fuentes de Archivel (Caravaca de la Cruz)», Actas de las XVII Jornadas de Patrimonio Histórico de la Región de Murcia (19 octubre - 23 noviembre de 2006), 119121, Murcia.

BROTÓNS, F., MUÑOZ, A. y GARCÍA, J., 2006b: «El castellum tardorrepublicano romano de Archivel (Caravaca de la Cruz, Murcia) y la presencia de contingentes militares permanentes en la cuenca alta de los ríos Argos y Quípar», Preactas del IV Congreso Hispano-Italiano histórico-arqueológico. Iberia e Italia: Modelos romanos de integración territorial (Murcia, 26-29 abril 2006), 111-112, Murcia.

BROTÓNS, F., MUÑOZ, A. y GARCÍA, J., 2008: «Contextos cerámicos de época republicana procedentes de enclaves militares ubicados en la cuenca del Argos-Quípar en el Noroeste de la Región de Murcia (España)», en J. UROZ, J.M. NOGUERA y F. COARELLI (Eds.), Actas del IV Congreso Hispano-Italiano histórico-arqueológico. Iberia e Italia: Modelos romanos de integración territorial (Murcia, 26-29 abril 2006), 545-560, Murcia.

BURILLO, F., IBAÑEZ, J. y POLO, C., 1993: Localización y descripción física del yacimiento y su entorno, Teruel.

CHAPA, T., 1992: «Caracterización económica de la alta Andalucía, durante la etapa ibérica plena y tardía», en A. MOURE (Ed.), Elefantes, ciervos y ovicaprinos. Economía y aprovechamiento del Medio en la Prehistoria de España y Portugal, 315-326, Santander.

GARCÍA, J.M., 1992: «Las necrópolis ibéricas en Murcia», en J. BLÁNQUEZ y V. ANTONA (Coords.), Congreso de Arqueología Ibérica: Las necrópolis, 313-347, Madrid.

GARCÍA, C. y MADRID, M.J., 2003: «Casa Noguera (Archivel, Caravaca de la Cruz)», Resumen de las XIII Jornadas de Patrimonio Histórico y Arqueología Regional (Murcia, del 5 al 8 de noviembre de 2002), 24-25, Murcia.

GARCÍA, L.A. y MARTÍNEZ, C., 2004: «Intervención arqueológica en Casa Noguera (Archivel, Caravaca de la Cruz)», Memorias de Arqueología, 12 (1997), 235-252.

GILMAN, A. y THORNES, J.B., 1985: El uso del suelo en la prehistoria del sureste de España, Madrid.

GONZÁLEZ ORTIZ, J.L., 1983: El Noroeste murciano. Estudio geográfico, Murcia.

GONZÁLEZ ORTIZ, J.L., 1984: «Notas para una Geografía Histórica del Noroeste murciano hasta el siglo XVI», Anales de la Universidad de Murcia. Letras XLII, 3-4 (curso 1983-1984), 193-230.

GRAU, I. y MORATALLA, J., 1998: El poblamiento de época ibérica en el Alto Vinalopó, Villena.

HABER, M., 2005: «Excavación arqueológica de urgencia en un solar de El Villar de Archivel (t.m. Caravaca de la Cruz, Murcia)», Actas de las XVI Jornadas de Patrimonio Histórico de la Región de Murcia, 260, Murcia.

IBORRA, M.P., 2000: «Los recursos ganaderos en época ibérica», Saguntum extra 3. Ibers. Agricultors, artesans i comerciants. III Reunió sobre economía en el Mòn Ibèric, 81-91.

LILLO CARPIO, P.A., 1986-1987: «Un singular tipo de exvoto: las pequeñas falcatas», Cuadernos de Prehistoria y Arqueología de la Universidad Autónoma de Madrid, 13-14, vol. II, 33-46. 
LILLO CARPIO, P.A., 1989: «Las vías de comunicación en época ibérica», en A. GONZÁLEZ BLANCO (Coord.), Los caminos de la Región de Murcia, 85-100, Murcia.

LILLO CARPIO, P.A., 1999: «El horizonte cultural ibérico en la cuenca del Segura», XXIV Congreso Nacional de Arqueología (Cartagena, 1997) tomo 3, 9-17, Murcia.

LÓPEZ GARCÍA, J., 1991a: «Clima, relieve e hidrología», en P. LÓPEZ GARCÍA (Ed.), El cambio cultural del IV al II milenios a.C. en la comarca Noroeste de Murcia 1, 119-133, Madrid.

LÓPEZ GARCÍA, J., 1991b: «Las transformaciones del medio físico: estudios geomorfológicos y erosivos», en $\mathrm{P}$. LÓPEZ GARCÍA (Ed.), El cambio cultural del IV al II milenios a.C. en la comarca Noroeste de Murcia 1, 193211, Madrid.

LÓPEZ GARCÍA, P., 1991: El cambio cultural del IV al II milenios a.C. en la comarca Noroeste de Murcia, Madrid.

LÓPEZ-MONDÉJAR, L., 2009a: «Vías de comunicación naturales, tradicionales e históricas con el mundo granadino a través del Noroeste murciano», Cuadernos de Prehistoria y Arqueología de la Universidad de Granada, 19, 393-410.

LÓPEZ-MONDÉJAR, L., 2009b: «Los castella tardorrepublicanos del Noroeste murciano en el marco del paisaje comarcal del siglo I a.C.: control del territorio y romanización en el Sureste peninsular», Zephyrus, vol. 64, (julio-diciembre, 2009), 97-113.

LÓPEZ-MONDÉJAR, L., 2010: «Los santuarios ibéricos del valle del Quípar (Murcia): carácter, localización y paralelos en el marco del Sureste peninsular», Quadernos de Prehistoria y Arqueologia de Castellò, 28, 175-189.

MADOZ, P., 1850 (Ed. facs. 1989): Diccionario geográficoestadístico-histórico de España y sus posesiones de ultramar. Región de Murcia, Murcia.

MATA, C. y BONET, H., 1992: «La cerámica ibérica: ensayo de tipología», Estudios de Arqueología Ibérica y Romana. Homenaje a Enrique Pla Ballester, Trabajos Varios del SIP 89, 117-173.

MELGARES, A., 1974: La carta arqueológica del término municipal de Caravaca de la Cruz, Universidad de Murcia, Tesis de Licenciatura.
MELGARES, A., 1990: «Un santuario ibérico en el 'Campo de Arriba' de Archivel. Término municipal de Caravaca (Murcia)», Homenaje a D. Jerónimo Molina, 163-171, Murcia.

MONEO, T., 2003: Religio Iberica. Santuarios, ritos y divinidades (siglos VII-I a.C.), Madrid.

MURCIA, A. y BROTÓNS, F., 2006: «Intervención arqueológica en el yacimiento romano de la Fuente de la Teja (Caravaca de la Cruz, Murcia): fases de ocupación», Memorias de Arqueología, 14 (1999), 185-212, Murcia.

PATITUCCI, S., 1972: «Il popolamento di età romana nell'antico Delta Padano. I. Valle del Mezzano», Atti e Memoria della Deputazione Ferrarese di Storia Patria s. III, XI, 37-99.

PÉREZ PICAZO, M.T., 1993: Caravaca de la Cruz 1755 según las respuestas generales del Catastro de Ensena$d a$, Madrid.

PRADOS, L., MOLINA, E. y ALVAREZ, C., 1991: «Las transformaciones del paisaje agrario en época histórica: estudio de las fuentes documentales», en P. LÓPEZ (Ed.), El cambio cultural del IV al II milenios a.C. en la comarca Noroeste de Murcia, vol. 1, 275-313, Madrid.

RAMALLO, S.F., 1991: «Un santuario de época tardorrepublicana en la Encarnación, Caravaca, Murcia», en Templos romanos en Hispania. Cuadernos de Arquitectura romana, 1, 39-65, Murcia.

SAN NICOLÁS, M., 1982: La investigación arqueológica en Caravaca. Síntesis, Caravaca.

SAN NICOLÁS, M., 1984: «El vaso cerámico con motivo solar de Caravaca (Murcia)», Anales de la Universidad de Murcia. Filosofía y Letras, XLII, No 3-4, curso $1983-$ 1984, 49-56.

SAN NICOLÁS, M., 1995: «Prehistoria y arqueología en la comarca noroeste de Murcia. Notas historiográficas», Alquipir, 5, año V, 24-40.

SERRANO, J. M. y GONZÁLEZ, J.L., 1985: Caravaca: centro comarcal del noroeste de Murcia, Murcia.

VICENT, J.M., 1991: «Fundamentos teórico metodológicos para un programa de investigación arqueo-geográfica», en P. LÓPEZ (Ed.), El cambio cultural del IV al II milenios a.C. en la comarca Noroeste de Murcia, vol. 1, 29-117, Madrid. 